\title{
Education to prevent ventilator-associated pneumonia in intensive care unit
}

\author{
Educação para prevenção da pneumonia associada à ventilação mecânica em unidade de terapia intensiva
}

Educación para la prevención de la neumonía asociada a la ventilación mecánica en una unidad de cuidados intensivos

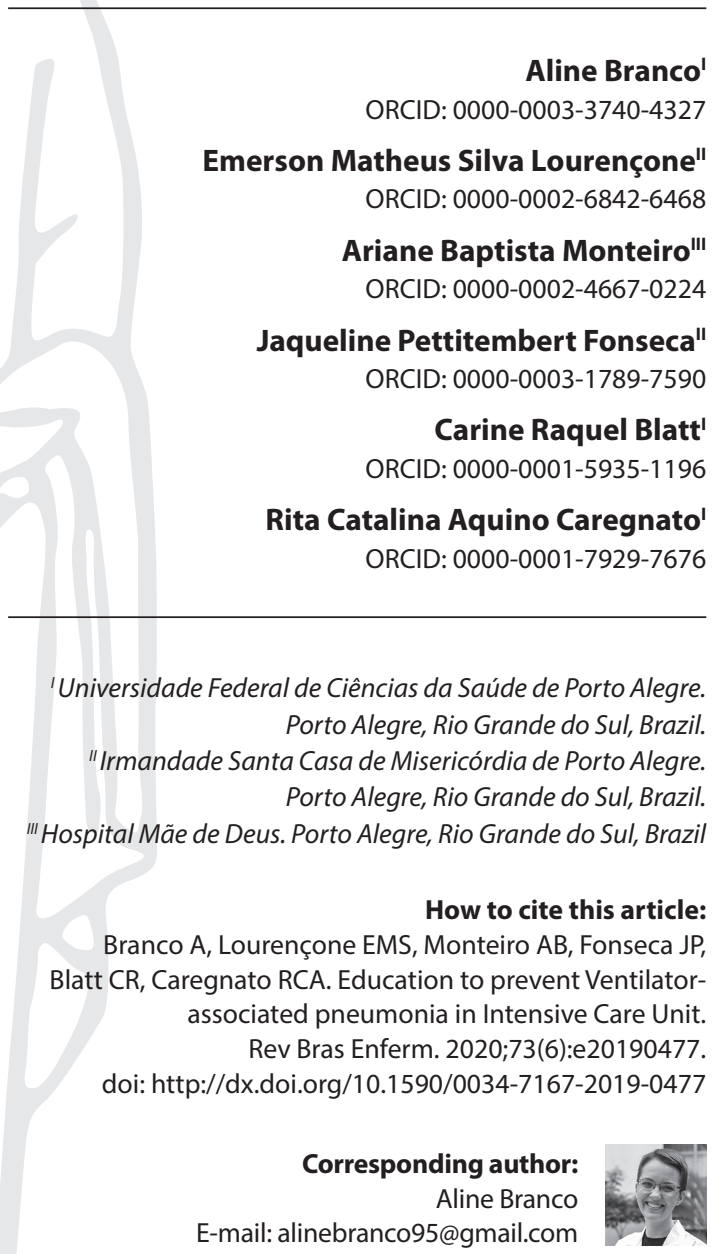

EDITOR IN CHIEF: Antonio José de Almeida Filho ASSOCIATE EDITOR: Fátima Helena Espírito Santo

Submission: 06-19-2019 Approval: 03-03-2020

\begin{abstract}
Objective: to evaluate nursing adherence to the Ventilator-Associated Pneumonia Prevention Bundle and the incidence rate, before and after Continuing education. Methods: a quasi-experimental, retrospective study with a total of 302 patients on mechanical ventilator admitted to the Intensive Care Unit. Data obtained from the application of the bundle, from June 2017 to June 2018. In December 2017, a training on the infection was carried out with 48 professionals. Results: the mean age of patients was $62.39 \pm 17.06$ years old. Appropriate measures before and after training, respectively: position of the ventilator filter $94.8 \%$ and $96.2 \%, \mathrm{p}=0.074$; elevated headboard $88.4 \%$ and $94.5 \%, p<0.001$; oral hygiene with chlorhexidine $89.5 \%$ and $98.2 \%, \mathrm{p}<0.001$; teeth brushing $80.8 \%$ and $96.4 \%, \mathrm{p}<0.001$; and cuff pressure $92.7 \%$ and $95.6 \%$, $p=0.002$. Incidence density was 7.99 for 4.28 infections $/ 1000$ ventilators per day. Conclusion: the bundle application and education made it possible to increase adherence and decrease infection.

Descriptors: Pneumonia, Ventilator-Associated; Intensive Care Unit; Education; Infection Control; Patient Safety.
\end{abstract}

\section{RESUMO}

Objetivo: avaliar a adesão da enfermagem ao bundle de prevenção à Pneumonia Associada à Ventilação Mecânica e a taxa de incidência, antes e após Educação Permanente. Método: estudo quase experimental, retrospectivo, com 302 pacientes em ventilação mecânica internados em Unidade de Terapia Intensiva. Dados foram obtidos da aplicação do bundle, de junho de 2017 a junho de 2018. Em dezembro de 2017, realizou-se capacitação com 48 pro-

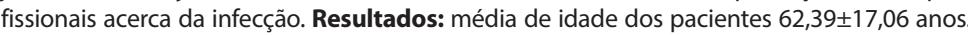
Medidas adequadas antes e após capacitação, respectivamente: posição do filtro do ventilador $94,8 \%$ e $96,2 \%, p=0,074$; cabeceira elevada $88,4 \%$ e $94,5 \%, p<0,001$; higiene oral com clorexidina $89,5 \%$ e $98,2 \%, p<0,001$; escovação dos dentes $80,8 \%$ e $96,4 \%, p<0,001$; e pressão do cuff $92,7 \%$ e $95,6 \%, p=0,002$. A densidade de incidência foi de 7,99 para 4,28 infecções/1000 ventiladores-mecânicos dia. Conclusão: a aplicação do bundle e a educação possibilitaram aumento da adesão e diminuição da infecção.

Descritores: Pneumonia Associada à Ventilação Mecânica; Unidades de Terapia Intensiva; Educação; Controle de Infecções; Segurança do Paciente.

\section{RESUMEN}

Objetivo: evaluar la adhesión de la enfermería al bundle (paquete) de prevención de la Neumonía Asociada a la Ventilación Mecánica y a la tasa de incidencia, antes y después de la Educación Permanente. Métodos: se trata de un estudio cuasiexperimental, retrospectivo, de 302 pacientes bajo ventilación mecánica ingresados en una Unidad de Cuidados Intensivos. Los datos se obtuvieron de la aplicación del bundle, desde junio de 2017 hasta junio de 2018. En diciembre de 2017 se realizó una capacitación de 48 profesionales sobre la infección. Resultados: la edad promedio de los pacientes era de $62.39 \pm 17.06$ años; las medidas adecuadas antes y después de la capacitación eran, respectivamente: posición del filtro del ventilador $94,8 \%$ y $96,2 \%, p=0,074$; cabecera elevada $88,4 \%$ y $94,5 \%, p<0,001$; higiene bucal con clorhexidina $89,5 \%$ y $98,2 \%$, $p<0,001$; cepillado de dientes $80,8 \%$ y $96,4 \%$, $\mathrm{p}<0,001$; $y$ presión del manguito (cuff) $92,7 \%$ y $95,6 \%, p=0,002$. La densidad de la incidencia era de 7,99 para 4,28 infecciones/1000 ventiladores-mecánicos día. Conclusión: la aplicación del bundle y la educación ayudaron a aumentar la adhesión y disminuir la infección. Descriptores: Neumonía Asociada a la Ventilación Mecánica; Unidades de Cuidados Intensivos; Educación; Control de Infecciones; Seguridad del Paciente. 


\section{INTRODUCTION}

Ventilator-Associated Pneumonia (VAP) is one of the complications related to the care of patients hospitalized in the Intensive Care Unit (ICU), which, according to consulted authors ${ }^{(1)}$, exceeds the mortality rates of other Healthcare Related Infections (HRI).VAP is the second most frequent infection in patients admitted to the ICU, as well as the most prevalent in patients who require invasive respiratory support ${ }^{(2)}$. The length of stay in the ICU for patients who developed VAP is $15.7 \pm 9.1$ days versus $4.9 \pm 4.9$ for those who were not affected, with mortality rates of $32 \%$ attributed to this infection $^{(3)}$. The impact of VAP can also be seen in the length of time of Mechanical ventilation (MV), with a difference of $14.3 \pm 15.5$ days of MV for patients who developed the infection, compared to $4.7 \pm 7.0$ days of $\mathrm{V}$ of those without pneumonia ${ }^{(4)}$.

Protocols can be used to prevent HRI, such as the VAP prevention bundle, which consists of a small grouping of the main evidence-based multidisciplinary practices to be used in a multidisciplinary way in Intensive Care ${ }^{(5-6)}$. Preventive measures, when applied together, will result in better outcomes than when implemented individually ${ }^{(7)}$. However, when there is any medical contraindication to apply a certain preventive measure in the bundle, it should be considered as performed and not as a failure to apply the protocol; thus, the bundle is considered to be complete ${ }^{(7)}$. Preventive measures are related to the drop in infection rates, reaching a reduction from 8.6 VAP/1000 ventilator days to $2.0 \mathrm{VAP} / 1000$ ventilator days ${ }^{(8)}$. The use of bundle to prevent VAP can contribute to reducing the number of days in the ICU, from 36 days to 27 days of stay ${ }^{(9)}$. Preventive actions are low-cost measures that can be easily applied, such as: headboard elevation between $30^{\circ}$ and $45^{\circ}$, oral hygiene with $0.12 \%$ mouthwash chlorhexidine, mechanical teeth brushing, endotracheal tube pressure evaluation and ventilator filter position ${ }^{(2)}$.

For the application of the prevention bundle to be successful, in order to lead to the reduction of VAP in the intensive care environment, the participation of nurses in the training and education of the team in relation to the work process is essential ${ }^{(10)}$. It is necessary to inform adherence data and incidence rates to professionals as feedback, in order to involve the whole team in care, inducing reflection on the care provided to critical patients, identifying what should be improved ${ }^{(11)}$. The encouragement of the team, through the education process, to reorganize care by recognizing the need for prevention and promoting quality of care, reaffirms the culture of patient safety within the ICU ${ }^{(12)}$.

In view of the results in the literature, on the need to prevent VAP in an Intensive Care environment, observed by the relationship of infection with the increase in the critical patient's stay on MV, ICU admission and hospital mortality, this study is justified to assess how the nursing team is adhering to preventive measures for VAP, and how the application of these preventive actions influence the infection incidence rates in the intensive care environment.

In addition, there is the importance of engaging and encouraging the team of professionals to adhere to preventive measures and apply them to all patients on ventilator support, incorporating them in their daily care. Therefore, it is necessary to carry out Continuing education through the articulation between teaching and service, it is proposed to transform the context of health practice by problematizing the work process and evidenced the need for change, with the participation and protagonism of the workers involved $^{(13)}$. From the involvement of professionals who provide intensive care to the patient, it is possible to analyze which aspects of assistance should be rethought and improved in order to provide assistance focused on safety and quality ${ }^{(12)}$.

Thus, the importance of assessing the contribution of the Continuing education to prevent VAP in the ICU is observed. So, the research question to be investigated was: how is the adherence to preventive measures for VAP and the incidence of infection in the intensive care environment before and after Continuing education in the ICU? Based on this problem, we decided to individually study each measure that composes the VAP bundle in relation to adherence by the nursing team before and after the Continuing education. Therefore, the intention was not to study the bundle, but each element that composes it.

\section{OBJECTIVE}

To evaluate nursing adherence to the VAP prevention bundle and the incidence rate, before and after conducting a Continuing education program.

\section{METHODS}

\section{Ethical aspects}

This study was submitted and approved by the Research Ethics Committee (REC) of the Hospital Institution. For the use of institutional information, a Term of Commitment for the Use of Medical Record Data was signed by the leader researcher, and the Declaration of Authorization by the Responsible Head signed by the ICU's lead physician. Both documents were submitted to REC with subsequent approval for conducting the research. All ethical norms foreseen in the Resolution of the National Health Council number 466/2012, were followed and met for the development of research with human beings.

\section{Design, period and setting of study}

This is a quasi-experimental study of before and after, retrospective, with a quantitative approach. It was conducted in a general adult ICU of a large hospital in Porto Alegre/RS, Brazil, from June 2017 to June 2018. The ICU attends patients from the Unified Health System - Sistema Único de Saúde (SUS), other health insurance and private ones, with a capacity of 20 beds, of which 5 are isolation box beds intended for hospitalization of patients under respiratory and contact precautions. We used the STROBE framework for observational studies.

\section{Population or sample; inclusion and exclusion criteria}

Intentional sample, consisting of the records made in the Ventilator-Associated Pneumonia Prevention Bundle of the 302 patients submitted to ventilator, admitted to the adult ICU from June 2017 to June 2018. All records of adherence to preventive measures applied by nursing to patients monitored while on artificial respiratory support, by endotracheal tube or tracheostomy, as well as records of patients undergoing spontaneous breathing tests were included in the study. 
Education to prevent ventilator-associated pneumonia in intensive care unit Branco A, Lourençone EMS, Monteiro AB, Fonseca JP, Blatt CR, Caregnato RCA.

\section{Study protocol}

The data regarding adherence of the nursing team to the VAP prevention bundle were collected through the records of the application to the 302 patients on MV, admitted to the ICU, accounting for a total of 2698 collections. In June 2017, the application of the preventive bundle in the ICU to patients on MV started, verifying as appropriate the preventive measures taken by the nursing staff, such as the position of the ventilator filter, when above the endotracheal tube insertion or tracheostomy, absent of dirt; headboard elevated between $30^{\circ} \mathrm{C}$ and $45^{\circ} \mathrm{C}$ when the patient's clinical condition allowed; oral hygiene with $0.12 \%$ chlorhexidine and teeth brushing registered in nursing evolution at $8 \mathrm{am}$ and 8pm; and cuff pressure, between 20 and $30 \mathrm{mmHg}$, recorded in nursing evolution at $8 \mathrm{am}$ and $8 \mathrm{pm}$. In this study, we sought to assess adherence to measures applied by nursing. To define the preventive measures to be contemplated in the bundle, interdisciplinary meetings among professionals working in the ICU were held, prior to the beginning of the use of the protocol, listing the most important measures that were appropriate to the context of the ICU under study.

VAP incidence density rate values were obtained from monthly reports issued by the Hospital Infection Control Service (HICS). Epidemiological surveillance of VAP happened through an active search in electronic medical records, such as prognostic, laboratory and imaging tests. Information regarding days spent on MV, length of stay in the ICU and hospital were collected from the EPIMED $^{\circledR}$ system. In December 2017, as a routine service of Continuing education in Health of the ICU, the training was carried out with a total of 48 nursing professionals. The training came at the request of the Unit's Coordinating Nurse, due to the increasing levels of VAP despite the application of preventive measures. It occurred on site, lasting 20 minutes each session. The topics of VAP diagnosis, risk factors and prevention strategies, presentation of the bundle, situation of the team's adherence to preventive measures and the importance of patient safety in the ICU were addressed through a multimedia resource. The research continued in a second stage through the collection and evaluation of the records of nursing adherence to the preventive measures of VAP, from January to June 2018. At the end of the data collection and analysis, it was demonstrated to all ICU nursing professionals, as feedback, adherence results and their influence on infection in patients. Thus, the data on the application of the VAP prevention bundle were compared before (from June to December 2017) and after (January to June 2018) Continuing education.

\section{Analysis of results and statistics}

The analysis occurred through descriptive statistics with relative and absolute frequencies, mean (or median), standard deviation, minimum and maximum. For statistical analysis, we used the Chi-square, Student's t-test and Mann-Whitney tests. A significance level of $5 \%(p<0.05)$ was adopted. Measures of association Odds Ratio with $95 \% \mathrm{Cl}$ of infection were also calculated for the outcome of death and VAP, with the factors of length of stay in the ICU, MV and hospital through simple logistic regression analysis. The data were stored in an electronic spreadsheet and the analyzes were carried out with the support of the statistical software SPSS version 23.

\section{RESULTS}

During the period, a total of 662 patients were admitted to the adult ICU. 302 of them required MV, submitted to 2698 applications of the VAP prevention bundle, accounting for a total of 13490 records of preventive measures. Comparing the patients before and after Continuing education, there was a significant difference between the ages, $(p<0.010)$, numerical difference of patients with VAP, in addition to the decrease of at least one day in MV, hospitalization in ICU and hospital as shown in Table 1.

The general adherence of the nursing team to the elements that compose the prevention bundle was $92.7 \%$. Analyzing the records considered to be adequate, there was a significant increase in adherence after Continuing education, Table 2. before the training, oral hygiene and teeth brushing had low adherence rates $89.5 \%$ and $80.8 \%$, respectively. After the activity, there is a significant increase $(p<0.001)$ for both measures.

Table 1 - Profile of patients admitted to the adult Intensive Care Unit, submitted to ventilator, before (June-December 2017) and after (January-June 2018) Continuing education, Porto Alegre, Rio Grande do Sul, Brazil, 2018

\begin{tabular}{|c|c|c|c|c|}
\hline Variable & $\begin{array}{l}\text { Before Continuing } \\
\text { education }\end{array}$ & $\begin{array}{l}\text { After Continuing } \\
\text { education }\end{array}$ & All the patients & $p$ value \\
\hline \multicolumn{5}{|l|}{ Gender } \\
\hline Female & $80(47.1 \%)$ & $64(48.1 \%)$ & $144(47.5 \%)$ & $p=0.946 \dagger$ \\
\hline Male & 89 (52.9\%) & 69 (51.9\%) & $158(52.5 \%)$ & \\
\hline Age & $64.63 \pm 16.69$ & $59.53 \pm 17.16$ & $62.39 \pm 17.06$ & $p<0.010 \neq$ \\
\hline Days of hospitalization with MV* & $9 \pm 15.6(1-75)$ & $8 \pm 20.76(1-182)$ & $9 \pm 18.03(1-182)$ & $p=0.739 \S$ \\
\hline Days in ICU* & $15 \pm 17.55(1-78)$ & $14 \pm 22.17(1-182)$ & $14 \pm 19.69(1-182)$ & $p=0.806 \S$ \\
\hline Hospitalization days* & $28 \pm 28.84(2-162)$ & $27 \pm 30.67(2-187)$ & $28 \pm 29.62(2-187)$ & $p=0.944 \S$ \\
\hline \multicolumn{5}{|l|}{ Outcome } \\
\hline Discharge & 72 (42.6\%) & $56(42.1 \%)$ & $128(42.4 \%)$ & $p=0.931+$ \\
\hline Death & 97 (57.4\%) & $77(57.9 \%)$ & $174(57.6 \%)$ & \\
\hline Patients with VAP & $14(8.2 \%)$ & $9(6.8 \%)$ & $23(7.6 \%)$ & $p=0.795 \dagger$ \\
\hline Total of patients & $169(55.9 \%)$ & $133(44 \%)$ & $302(100 \%)$ & - \\
\hline
\end{tabular}

Note: *presented as median \pm standard deviation (min - max). +Chi-square test, $\neq$ Student $t$ test and \$Mann-Whitney. Ventilator-associated pneumonia (VAP); mechanical ventilator (MV); Intensive Care Unit (ICU). 
Table 2 - Adherence and registration of the nursing team to the Ventilator-Associated Pneumonia prevention bundle before (June-December 2017) and after (January-June 2018) Continuing education in an adult Intensive Care Unit, Porto Alegre, Rio Grande do Sul, Brazil, 2018

\begin{tabular}{|c|c|c|c|c|}
\hline $\begin{array}{l}\text { Bundle preventive measures } \\
n=13490\end{array}$ & $\begin{array}{l}\text { Before Continuing education } \\
\qquad \begin{array}{c}n(\%) \\
n=6735\end{array}\end{array}$ & $\begin{array}{l}\text { After Continuing education } \\
\qquad \begin{array}{l}n(\%) \\
n=6755\end{array}\end{array}$ & $p$ value* & $\begin{array}{l}\text { General adherence } \\
\text { to the measures (\%) }\end{array}$ \\
\hline Filter position & $1277(94.8)$ & $1300(96.2)$ & $\mathrm{p}=0.074$ & 2577 (95.5) \\
\hline Elevated headboard & $1191(88.4)$ & $1277(94.5)$ & $p<0.001$ & $2468(91.5)$ \\
\hline Oral hygiene & 1206 (89.5) & $1327(98.2)$ & $\mathrm{p}<0.001$ & $2533(93.9)$ \\
\hline Teeth brushing & $1088(80.8)$ & 1303 (96.4) & $p<0.001$ & 2391 (88.6) \\
\hline Cuff pressure & 1249 (92.7) & 1292 (95.6) & $p=0.002$ & 2541 (94.2) \\
\hline $\begin{array}{l}\text { Total appropriate records } \\
(\mathrm{n}=12510)\end{array}$ & $6011(89.2)$ & 6499 (96.2) & $p<0.001$ & $12510(100)$ \\
\hline
\end{tabular}

Note: *Chi-Square test.

Table 3 - Association between adherence and registration per patient of the Ventilator-Associated Pneumonia Prevention Bundle with the variables: days spent in ventilator, in the Intensive Care Unit and hospital. Porto Alegre, Rio Grande do Sul, Brazil, 2018

\begin{tabular}{|c|c|c|c|c|c|c|}
\hline \multicolumn{7}{|c|}{ Adequacy to preventive measure } \\
\hline Variable & \multicolumn{2}{|c|}{$\begin{array}{c}\text { Lower than } \% \text { average of adherence and registration } \\
\text { Filter position Elevated headboard }\end{array}$} & $\mathbf{x}$ & \multicolumn{3}{|c|}{$\begin{array}{l}\text { Higher than the \% average of adherence and registration } \\
\text { Oral hygiene } \quad \text { Teeth brushing Cuff pressure }\end{array}$} \\
\hline MV days & $\begin{array}{c}19 \pm 25.70 \\
(1-182) x \\
7 \pm 13.49 \\
(1-75) \\
\mathbf{p}<0.001^{*}\end{array}$ & $\begin{array}{c}15 \pm 16.94 \\
(2-70) \times \\
7 \pm 18.14 \\
(1-182) \\
\mathbf{p}<0.001 *\end{array}$ & & $\begin{array}{l}15 \pm 16.42 \\
(1-74) x \\
8 \pm 18.41 \\
(1-182) \\
p=0.002^{*}\end{array}$ & $\begin{array}{l}11 \pm 16.02 \\
(1-75) x \\
8 \pm 18.88 \\
(1-182) \\
p=0.016^{*}\end{array}$ & $\begin{array}{c}23 \pm 18.14 \\
(1-70) x \\
7 \pm 17.27 \\
(1-182) \\
\mathbf{p}<0.001 *\end{array}$ \\
\hline ICU stay days & $\begin{array}{c}27 \pm 26.43 \\
(2-182) \times \\
12 \pm 15.66 \\
(1-80) \\
\mathbf{p}<0.001 *\end{array}$ & $\begin{array}{c}19.5 \pm 19.51 \\
(2-82) \times \\
12 \pm 19.28 \\
(1-182) \\
\mathbf{p}<0.001^{*}\end{array}$ & & $\begin{array}{c}18.5 \pm 18.45 \\
(1-74) x \\
13 \pm 19.98 \\
(1-182) \\
p=0.015^{*}\end{array}$ & $\begin{array}{c}17 \pm 17.76 \\
(1-80) x \\
13 \pm 20.49 \\
(1-182) \\
p=0.025^{*}\end{array}$ & $\begin{array}{c}27 \pm 21.29 \\
(1-82) \times \\
12 \pm 18.28 \\
(1-182) \\
\mathbf{p}<\mathbf{0 . 0 0 1 *}\end{array}$ \\
\hline $\begin{array}{l}\text { Hospitalization days } \\
\text { Hospital }\end{array}$ & $\begin{array}{c}43 \pm 33.52 \\
(8-187) \times \\
24 \pm 27.17 \\
(2-162) \\
p<0.001 *\end{array}$ & $\begin{array}{c}32.5 \pm 27.21 \\
(2-124) x \\
25.5 \pm 30.41 \\
(2-187) \\
p=0.010^{*}\end{array}$ & & $\begin{array}{c}34.5 \pm 30.68 \\
(2-162) \times \\
27 \pm 29.06 \\
(2-187) \\
p=0.034^{*}\end{array}$ & $\begin{array}{c}31 \pm 29.54 \\
(2-162) \times \\
26 \pm 29.57 \\
(2-187) \\
p=0.065^{*}\end{array}$ & $\begin{array}{c}53.7 \pm 32.59 \\
(2-137) \times \\
24 \pm 27.23 \\
(2-187) \\
p<0.001 *\end{array}$ \\
\hline
\end{tabular}

Note: presented as median \pm standard deviation (min - max), ( $n=302$ patients). ${ }^{*}$ Mann-Whitney test. Mechanical Ventilator (MV); Intensive Care Unit (ICU),

We carried out the verification of adherence and registration of adequacy to preventive measures per patient, analyzing the number of MV days, ICU and hospital stay days, for the average percentage of records considered below and above the average adequacy, for all preventive measures. The cutoff values were considered as the average percentage of adherence to the measures based on the 2698 records per patient: position of the ventilator filter (95.5\%); elevated headboard between $30^{\circ} \mathrm{C}$ and $45^{\circ} \mathrm{C}$ (91.5\%); oral hygiene with chlorhexidine $0.12 \%$ (93.9\%); teeth brushing (88.6\%); and cuff pressure of the endotracheal tube (94.2\%). It is observed that the number of days on MV, ICU and in hospital stay days obtained higher values when adherence to preventive measures was lower than the average percentage of adequacy observed in the records, as can be seen in Table 3.

From June 2017 to June $2018,62.2 \%$ of the patients daily monitored were using MV; the incidence of VAP in one year was concentrated in 7.61\%; while the mean incidence density rate for VAP was 5.06 VAP/1000 MV-day. Comparing the incidence density of VAP, in the first semester of 2017 - before starting the application of the prevention bundle to critically ill patients on $\mathrm{MV}$, it was concentrated in 7.99VAP/1000 MV-day, and in the second semester 2017 decreased to 4.28VAP/1000 V-day. There is a decrease in the density of the incidence of infection for the months following the application of preventive measures, as well as after training, Figure 1.

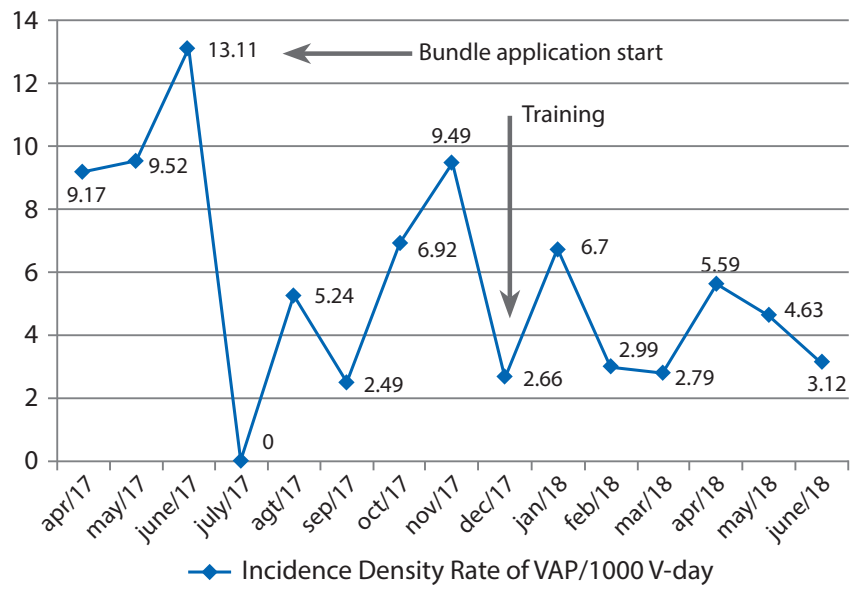

Note: Ventilator-associated pneumonia (VAP); mechanical ventilator (MV).

Figure 1 - Incidence Density Rate of Ventilator-Associated Pneumonia during the period of application of the preventive bundle, before (JuneDecember 2017) and after (January-June 2018) Continuing education in the adult Intensive Care Unit, Porto Alegre, Rio Grande do Sul, Brazil, 2018

Analyzing the behavior for days spent on $\mathrm{MV}$, in the ICU and hospital, we verify that: each day on MV increases by $6 \%$ (OR=1.060; $95 \% \mathrm{Cl}: 1.03-1.08 ; \mathrm{p}<0.001)$ the chance of having VAP; each day in ICU increases by $4.7 \%$ (OR=1.047; 95\% Cl: $1.02-1.07 ; \mathrm{p}<0.001)$ the chance of having VAP; and each day in the hospital increases 
by $1.7 \%(\mathrm{OR}=1.017 ; 95 \% \mathrm{Cl}: 1.01-1.03 ; \mathrm{p}=0.004)$ the chance of having VAP. we observed that having VAP increased the chance of death by $41.5 \%$ in relation to patients without infection $(\mathrm{OR}=1.41$; $95 \% \mathrm{Cl}: 0.58-3.47 ; \mathrm{p}=0.445)$, although the last one did not have statistical significance.

\section{DISCUSSION}

From June 2017 to June 2018, the average incidence density rate was 5.06 VAP/1000 MV-day, with an incidence of $7.61 \%$ new cases, and an average use of ventilator in $62,2 \%$ per patient-day, similar to the results found in other studies ${ }^{(14)}$. VAP is the most prevalent infection in the ICU, when compared to the other $\mathrm{HICS}^{(2,8)}$. Mortality and days spent in the ICU for VAP are shown to be superior to infection related to blood and vesical catheter ${ }^{(14)}$. MV days, ICU admission and hospital were risks for the development of the infection. Studies highlight the impact of VAP on the increase in days spent in the ICU, V, with the direct relationship on mortality rates in intensive care ${ }^{(3-4)}$.

Considering the impact of VAP on patient recovery, health institutions have been intensely concerned in recent years to appropriate measures that can be used effectively to reduce ICU rates ${ }^{(15)}$. Bundles, containing multidisciplinary preventive measures to be applied together, are an excellent method of guaranteeing safe care ${ }^{(16-18)}$. The success of its implementation to reduce infection in the ICU is described in relevance in the international literature ${ }^{(6,15,17-21)}$. A meta-analysis published in 2018 demonstrated the reduction of VAP-related mortality after the implementation of a preventive bundle ${ }^{(18)}$.

In the adult ICU, immediately after the bundle was implanted, the density rate of VAP incidence in the ICU was 13.11 infections/1000 MV-day. After application, the rate of pneumonia decreased in August 2017 to 5.24 infections/1000 MV-day. The incidence density value in July 2017 was considered to be inconsistent with the context; it infers that due to the absence of nurses in the Hospital Infection Control Service (HICS) in that month, monitoring failure occurred. The same should not be considered for the other months, which had realistic monthly observation of patients for the development of VAP in the ICU by the HICS. The incidence of VAP in June 2017 exceeded that recommended by the Municipal Coordination of Hospital Infection Control of Porto Alegre (MCHIC), whose guidance for ICUs was to keep VAP to a maximum of 9.6 infections/1000 MV-day ${ }^{(22)}$. The National Healthcare Safety Network recommends that hospitals keep the VAP incidence density at $1.60 / 1000 \mathrm{MV}$-day ${ }^{(23)}$. For subsequent months, there was a marked decrease in the density of incidence of infection in the adult ICU.

A study carried out between 2013 and 2015 in Egypt demonstrated the impact of preventive measures to decrease VAP rates, with a drop from 25/1000 V-day in 2013 to 6/1000 V-day in 2015 , reporting the effective influence of the bundle for decrease in the incidence of infection among patients ${ }^{(20)}$. Other international studies report success with the application of a package of measures to reduce VAP(15,17). However, when adopting a measurement protocol, health institutions must maintain vigilance and records, since only applying it without adherence audit, makes it impossible to know the team's performance in adhering to preventive measures for all critical patients ${ }^{(9)}$. Likewise, considering the increased VAP rates in the ICU simultaneously with the lack of records of professionals' adherence, make it impossible to assess which aspect is lacking for the correct application of practical actions and how can we think of ways to correct it ${ }^{(5)}$. In this study, the general adherence to the elements of the bundle was very satisfactory, reaching $92.7 \%$ of adequacy for all preventive measures, similar to another study that points to $95 \%$ adherence to all preventive actions ${ }^{(24)}$.

This result is also in line with a study conducted in Saudi Arabia, which reached $94.2 \%$ adherence after the formation of a structured team for the prevention of VAP in the ICU, with a drop between 2011 and 2013 from 8,6/1000 MV-day to 2.0/1000 MV-day ${ }^{(19)}$. In the adult ICU, the team best adhered to the filter position (95.5\%) and cuff pressure (94.2\%), with less adequacy for teeth brushing (88.6\%). On the other hand, in another study, less adherence was recorded to keep the headboard elevated (94\%), but after the effective implementation of the bundle, it increased to $99 \%$ at the end of the project ${ }^{(24)}$.

Some authors talk about the need for daily evaluation of the bundle and not only monthly, with audits and feedback to the team about their behavior towards adherence, being able to observe the reasons for the inadequacy of practical actions ${ }^{(1,25)}$. Thus, when building the package of measures and implementing it in the ICU, it is necessary to present it to all team members, and to clarify its importance for the effective participation of all professionals for the success of preventive measures and consequent drop in infection rates $\mathrm{s}^{(1,25)}$.

Professional education, based on the changing needs observed during care, can be a great ally for the successful implementation of a preventive bundle, knowledge and awareness of the team, and a consequent reduction in infection rates in the ICU $(16,26)$. In the study, despite the decrease in the density of VAP incidence compared to the semester prior to the adoption of the bundle in the ICU, in the months following application to patients on ventilator, two alarming indicators were found: simultaneously to the increase in the density of VAP incidence in November 2017 with 9.49/1000 MV-day, low adherence to teeth brushing and oral hygiene was observed when compared to other preventive measures.

Thus, the need to change this scenario was evidenced, based on the principle that all nursing professionals should reinforce the need and importance of the correct application of prevention measures and its impact to reduce the VAP indicators in the ICU. The importance of Continuing education for prevention is emphasized: time to assess what are the gaps in care and what should be improved, to ensure safe and risk-free care for the patient ${ }^{(11)}$.

When verifying non-adherence to a certain preventive measure, education is an ally, for the opportunity to initiate dialogue and awareness of professionals about the need for prevention in the intensive care environment ${ }^{(10)}$. A study conducted in Taiwan demonstrated the impact of educational actions with professionals, that after a series of educational programs, the VAP values decreased from 2.84/1000 MV-day to 1.31/1000 MV-day; with $98 \%$ adherence to hand hygiene for nurses (superior to doctors $97 \%$ and physiotherapists 95\%) and general adherence to all measures in $87 \%$. The adequacy values for cuff pressure measurements, 
Education to prevent ventilator-associated pneumonia in intensive care unit Branco A, Lourençone EMS, Monteiro AB, Fonseca JP, Blatt CR, Caregnato RCA.

oral hygiene, elevated headboard and position of the ventilator filter were similar to those found in this study ${ }^{(26)}$.

In order to education to really have an impact, continuous supervision of the bundle is necessary for proper implementation $^{(9,27)}$. Providing feedback about the behavior and influence of the VAP values to the team, makes professionals feel part of the change process and responsible for the success of the indicators and the promotion of safe care. For continuous monitoring, education, effective participation of nursing and HICS must work together, by providing data on the team's performance in the applicability of actions to patients, the influence on the VAP indexes provided by infection control and the constant training of professionals to adapt care ${ }^{(9)}$.

Hospital administration must be constantly involved and supporting the use of team protocols and education to avoid infection, improve hospital indicators and ensure quality care for patients ${ }^{(16)}$. Likewise, the importance of organizing a VAP team is evident: multidisciplinary, with the participation of all professionals who provide assistance, in order to delimit together the preventive measures that fit the context of their ICU, to create a protocol sufficiently comprehensible to patients assisted and pass it to the team of technicians and other professionals, for the success of the measures and impact on the reduction of the $\mathrm{HRI}^{(9,26)}$.

\section{Limitation of the study}

This study has some limitations. The impossibility of collecting data from the Acute Physiology And Chronic Health Evaluation (APACHE) II occurred due to incomplete information about the patient's profile in the EPIMED ${ }^{\circledR}$ system. This data would make it possible to verify the existence of any correlation among the days of ICU stay, days spent on ventilator or in hospital for patients, with the APACHE II score. We can also mention the Hawthorne Effect: due to the application of the preventive bundle, professionals, when perceiving themselves observed, may have been instigated to perform a certain measure, such as elevation of the headboard that was not properly positioned at the time, for example. The training with professionals was only one day, although it was in all shifts, which could extend to other periods and use other methodological forms of education.

\section{Contributions to the area of nursing, health or public policy}

We verified the importance of engaging the nursing team to awareness of preventive measures, in order to reduce infection rates and promote the safety of critical patients. We believe that this study provides the opportunity to carry out other subsequent studies for VAP, such as a complete evaluation of the bundle with audits for the preventive measures of all professionals; use of other learning modalities; as well as raising the economic costs between expenses for application of the prevention protocol and for treatment of the infection, reinforcing the importance of the tool.

\section{CONCLUSION}

Through continuous surveillance of VAP prevention measures and Continuing education with all nursing professionals in the ICU, there was an increase in adherence to preventive measures right after training, with the concomitant numerical decrease in the incidence of VAP and a reduction incidence density rate/1000 MV-day.

Through Continuing education, it is possible to associate health education with the workplace as a setting and professionals as active participants in change actions. In association, the importance of daily feedback with the team on the behavior for adherence to preventive measures is observed, enabling the daily reflection of the assistance provided by the professionals, for changes in practice in favor of the safety of the assisted patient. The bundle proved to be an important tool that should be incorporated daily in care, for the promotion of critical patient safety in the ICU.

\section{REFERENCES}

1. Ali HIE, Rayan AA, Ibrahim TH. Root cause analysis of ventilator-associated pneumonia and the effect of analysis of expanded ventilator bundle of care. J Anaesthesiol. 2016;9(2):170-177. doi: 10.4103/1687-7934.182223

2. Mehta A, Bhagat R. Preventing ventilator-associated infections. Clin Chest Med. 2016;37(4):683-692. doi: 10.1016/j.ccm.2016.07.008

3. Karaoglan H, Yalcin AN, Cengiz M, Ramazanoglu A, Ogunc D, Hakan R, Yilmaz M, et al. Cost analysis of ventilator-associated pneumonia in Turkish medical-surgical intensive care units. Infez Med [Internet]. 2010 [cited 2019 Jun 14];18(4):248-55. Available from: https://www.ncbi. nlm.nih.gov/pubmed/21196819

4. Amin Alpesh. Clinical and economic consequences of ventilator-associated pneumonia. Clin Infect Dis. 2009;1 (49):36-46. doi: $10.1086 / 599814$

5. DeLuca LA, Walsh P, Davidson Jr DD. Impact and feasibility of an emergency department-based ventilator associated pneumonia bundle for patients intubated in an academic emergency department. Am J Infect Control. 2017;2(45):151-7. doi: 10.1016/j.ajic.2016.05.037

6. Saint $\mathrm{S}$, et al. What US hospitals are currently doing to prevent common device-associated infections: results from a national survey. Qual Saf Health Care. 2019;0:1-9. doi: 10.1136/bmjqs-2018-009111

7. Resar R, Griffin FA, Haraden C, Nolan TW. Using care bundles to improve health care quality. IHI Innovation Series white paper. Cambridge, Massachusetts: Institute for Healthcare Improvement; [Internet]. 2012 [cited 2019 Ou. 13]. Available from: www.IHI.org

8. Khan HA, Baig FK, Mehboob R. Nosocomial infections: epidemiology, prevention, control and surveillance. Asian Pac J Trop Biomed. 2017;7(5):478-482. doi: 10.1016/j.apjtb.2017.01.019 
Education to prevent ventilator-associated pneumonia in intensive care unit Branco A, Lourençone EMS, Monteiro AB, Fonseca JP, Blatt CR, Caregnato RCA.

9. Parisi M, Gerovasili V, Dimopoulos S, Kampisiouli E, Goga C, Perivolioti E, et al. Use of ventilator bundle and staff education to decrease ventilator-associated pneumonia in intensive care patients. Crit Care Nurse. 2016;36(5):1-7. doi: 10.4037/ccn2016520

10. Alcan AO, Korkmaz FD, Uyar M. Prevention of ventilator-associated pneumonia: Use of the care bundle approach. Am J Infect Control. 2016;44(10):e173-e176. doi: 10.1016/j.ajic.2016.04.237

11. Mansano FPN, Belei RA, Vinci LAS, Melo BLD, Cardoso LTQ, Garcia JCP, et al. Impact of educational action in maintaining high decubitus as preventive measure of ventilator-associated pneumonia in the Intensive Care Unit. Arq Bras Ciênc Saúde. 2016;42(1):21-6. doi: 10.7322/ abcshs.v42i1.945

12. Mello JF, Barbosa SFF. Cultura de segurança do paciente em unidade de terapia intensive: perspectiva da equipe de enfermagem. Rev Eletrônica Enferm. 2017;19(7):1-12. doi: 10.5216/ree.v19.38760

13. Mello AL, Brito LJS, Terra MG, Camelo SHH. Weaving the permanent health education in the hospital context: experience report. Esc Anna Nery. 2018;22(1):1-5. doi: 10.1590/2177-9465-ean-2017-0192

14. Parajuli NP. Epidemiology of device-associated infections in an intensive care unit of a teaching hospital in Nepal: a prospective surveillance study from a developing country. Am J Infect Control. 2017;45(9):1024-9. doi: 10.1016/j.ajic.2017.02.040

15. Cutler LR, Sluman P. Reducing ventilator associated pneumonia in adult patients through high standards of oral care: A historical control study. Intensive Crit Care Nurs;30(2):61-8. doi: 10.1016/j.iccn.2013.08.005

16. Hassan Z, Wahsheh M. Knowledge level of nurses in Jordan on ventilator-associated pneumonia and preventive measures. Nurs Crit Care. 2017;22(3):125-32. doi: 10.1111/nicc.12273

17. Álvarez-Lerma F, Palomar-Martínez M, Sánchez-García M, Martínez-Alonso M, Álvarez-Rodríguez J, Lorente L, et al. Prevention of VentilatorAssociated Pneumonia: the multimodal approach of the Spanish ICU “Pneumonia Zero" Program. Crit Care Med. 2018;46(2):181-8. doi: 10.1097/CCM.0000000000002736

18. Pillegi C, Mascaro V, Bianco A, Nobile CG, Pavia M. Ventilator bundle and its effects on mortality among ICU patients: a meta-analysis. Crit Care Med;46(7):1167-74. doi: 10.1097/CCM.0000000000003136

19. Khan R, et al. The impact of implementing multifaceted interventions on the prevention of ventilator associated-pneumonia. Am J Infect Control;44(3):320-6. doi: 10.1016/j.ajic.2015.09.025

20. Samra SR, Sherif DM, Elokda SA. Impact of VAP bundle adherence among ventilated critically ill patients and its effectiveness in adult ICU. Egypt J Chest Dis Tuberc. 2017;66(1):81-86. doi: 10.1016/j.ejcdt.2016.08.010

21. Yazici G, Bulut H. Efficacy of a care bundle to prevent multiple infections in the intensive care unit: A quasi-experimental pretest-posttest design study. Appl Nurs Res. 2018;39:4-10. doi: 10.1016/j.apnr.2017.10.009

22. Coordenação Municipal de Controle de Infecção Hospitalar (CMCIH). Boletim Informativo da Coordenação Municipal de Controle de Infecção Hospitalar de Porto Alegre [Internet]. 2016 [cited 2019 Jun. 15]. Available from: http://www2.portoalegre.rs.gov.br/cgvs/default.php?p_secao=427

23. National Healthcare Safety Network (NHSN). Patient Safety Component Manual[Internet]. CDC. 2019 [cited 2019 Jun. 15]. Available from: https://www.cdc.gov/nhsn/pdfs/pscmanual/pcsmanual_current.pdf

24. Marini AL, Khan R, Mundekkadan S. Multifaceted bundle interventions shown effective in reducing VAP rates in our multidisciplinary ICUs. BMJ Qual Improv Rep. 2016;5(1):1-4. doi: 10.1136/bmjquality.u205566.w2278

25. Klompas M, Lil L, Kleinman K, Szumita PM, Massaro AF. Associations Between Ventilator Bundle Components and Outcomes. JAMA Intern Med. 2016;176(9):1277-1283. doi: 10.1001/jamainternmed.2016.2427

26. Kao CC, Chiang HT, Chen CY, Hung CT, Chen YC, Su LH, et al. National bundle care program implementation to reduce ventilator-associated pneumonia in intensive care units in Taiwan. J Microbiol Immunol Infect. 2017;(17):S1684-1182. doi: 10.1016/j.jmii.2017.11.001

27. Hamishehkar H, Vahidinezhad M, Mashayekhi SO, Asgharian $\mathrm{P}$, Hassankhani H, Mahmoodpoor A. Education alone is not enough in ventilator associated pneumonia care bundle compliance. J Res Pharm Pract. 2014;3(2) 51-5. doi: 10.4103/2279-042X.137070 